\title{
LA MÁXIMA COMO FORMA Y COMO TEXTO
}

\section{Carles Besa Camprubí}

\author{
Universitat Pompeu Fabra
}

Tres apartados componen el presente trabajo. En el primero de ellos («La máxima como forma») nos ocupamos de la retórica del género de la máxima y de los problemas que suscita todavía hoy, no sin hacer un repaso crítico de la bibliografía generada por la cuestión; en este sentido, abundamos en las limitaciones inherentes a un análisis puramente gramatical (morfológico y sintáctico), cuyo principal error, a nuestro entender, consiste en la creencia de que la máxima emergería menos de la libertad creadora del autor que de un código al que aquél se vería obligado a someterse, y que, como tal, limitaría considerablemente el número de realizaciones posibles. En el segundo apartado («La máxima como texto») reivindicamos, precisamente, el estatuto ficticio y subjetivo de la máxima, la cual interesaría menos por su enunciado que por su enunciación, menos por lo que dice — su contenido, a menudo banal, pues sólo un lector cándido creerá en su verdad ideológica- y por cómo lo dice - su forma, constante y poco variable- que por su función en tanto que ilustración de quien habla; la máxima es, pues, entendida como una verdad personal que aprovecha las estrategias 
sacadas de una retórica ampliamente experimentada para «venderse» a sí misma como un sello de autenticidad anónima. En el tercer y último apartado («Máxima, Witz y adivinanza»), y recurriendo principalmente a Jolles y a Todorov, recuperamos parte de los elementos vistos anteriormente a través de la comparación de la máxima con otras dos formas breves demasiado a menudo negligidas por la crítica ${ }^{1}$.

\section{LA MÁXIMA COMO FORMA}

Es sabido que, pese a las divergencias entre los autores y los tiempos, el género de la máxima obedece a unos esquemas formales relativamente fijos y poco diversificados; dicha inamovilidad retórica ha originado, sin duda, no pocas aproximaciones en sentido análogo, muchas de las cuales nada o poco han aportado a los estudios de los investigadores pioneros. En este contexto, goza todavía de una aprobación muy generalizada la contribución de Meleuc (1969: 70), quien, partiendo del modelo generativo-transformacional -y rechazando voluntariamente cualquier compromiso con la lingüística del discurso-, reduce la máxima a un tipo concreto de enunciado: aquel que realizaría al nivel de la frase el esquema general (hiperbólico) «affirmation, il, partout, toujours». Meleuc repasa, asimismo, las características de cada uno de los componentes del género. Así, los artículos, que tendrían por función situar el nombre en el universal de la lengua, serían una especie de obligación gramatical, y por ello estarían desprovistos de todo referente perceptible (el determinado es «la somme des individualités» y el indeterminado, «l'extension de l'individualité»); los demostrativos, al actuar como un mero procedimiento enfático, no constituirían más que una variación estilística del artículo; por lo que se refiere a los pronombres, Meleuc destaca la importancia, en

1 La falta de espacio nos impide tratar aquí el tema de la máxima como texto dentro de otro texto, es decir, como parte integrante de un discurso más amplio (por ejemplo, la novela); en este ámbito, la máxima no sería tanto una forma o un género como un tipo de palabra, una fuerza en el texto que la alberga. Es evidente que examinar la máxima por sí misma conlleva una idea peligrosa y desgraciadamente muy extendida: nos referimos a la opinión que se suele tener de ella como discurso «no funcional» en la economía del texto, que, si es el caso, la incluye, es decir, como fragmento insular - «autocomunicativo», dice Biason (1990:120) apoyándose en Lotman. Remitimos, para una aproximación, al extraordinario trabajo de Bennington (1985) y a nuestros dos artículos (Besa, 1994 y en prensa). 
francés, del indefinido «on», encargado de representar el universal de los agentes; y en cuanto al sistema verbal, subraya el protagonismo de las formas de la aserción pura («est», «il y a»), del presente y del infinitivo. En lo relativo a su sintaxis, la máxima podría ser resumida por la fórmula «Enunciado del lector + NEG» o «transformación negativa», con la que Meleuc indica que estamos ante un enunciado cuya principal característica consiste en invertir un extratexto anterior -la doxa, el pretexto supuestamente correcto del lector, es decir, conforme a las reglas de la lengua (Meleuc, 1969: 84) ${ }^{2}$.

Ciertamente, una aproximación de este tipo puede suscitar muchas reservas. En primer lugar, no aporta ningún dato realmente nuevo a aquellos lectores que sabemos intuitivamente reconocer una máxima -y si la reconocemos es en virtud de su estructura, objeto del estudio de Meleuc-; en segundo lugar, podemos considerar apriorística la concepción subyacente de la supremacía del código por encima del mensaje, de la langue como sistema inmaculado e inalterable por la parole de un sujeto enunciador que no deja de revelarse tras este discurso supuestamente impersonal.

Unos años antes, Benveniste no había llegado mucho más lejos, pese a su innegable lucidez y al interés netamente más globalizador de sus observaciones. Nos referimos a sus famosos artículos «La phrase nominale» $\mathrm{y}$ «Les relations de temps dans le verbe français» (Benveniste, 1950 y 1959 = 1966), en los que, sin embargo, proporciona algunas pistas de cara al estudio de la máxima no ya como género autónomo (como hacen Meleuc y la gran mayoría de los críticos), sino dentro de un contexto más amplio. En el primer artículo, Benveniste alude a Píndaro y a Herodoto para oponer la frase nominal a la frase verbal («phrase à $\varepsilon \sigma \tau \imath »)$ : la frase nominal, siempre ligada al discurso directo y utilizada para aserciones de carácter general, es intemporal, impersonal y amodal, y actúa como argumento de autoridad, prueba o referencia introducida para convencer y no para informar ${ }^{3}$; contrariamente, la

2 Por ello arguye Meleuc (1969) que la máxima sería un enunciado didáctico polémico, ya que intenta contradecir un cierto enunciado previo del lector, sede de sus prejuicios, de sus falsas ideas sobre la vida y el mundo. Así, por ejemplo, en la célebre máxima de La Rochefoucauld: «Ce que les hommes ont nommé amitié n'est qu'une société, qu'un ménagement réciproque d'intérêts et qu'un échange de bons offices [...]», «les hommes»-los cuales, como se ve, se equivocan en su apreciación de la amistad-, seríamos los lectores, pobres ilusos.

3 Perelman (1988: 216-217) afirmará también, desde su perspectiva argumentativa, que el presente es el tiempo que mejor expresa lo normal en su paso hacia la norma, y que el pronombre «on» transforma en normal lo subjetivo. 
frase verbal es adecuada para la narración de un hecho y para la descripción de una manera de ser o de una situación. En el segundo artículo, esta distinción se ve doblada por la famosa oposición entre histoire («Personne ne parle ici; les événements semblent se raconter eux-mêmes») y discours, en el que entran «tous les genres où quelqu'un s'adresse à quelqu'un, s'énonce comme locuteur et organise ce qu'il dit dans la catégorie de la personne» (Benveniste, 1959: 241-242).

No hay duda de que la densidad formal y la estrategia discursiva de la máxima son de una gran habilidad y que, por ello, puede ofrecer, como quiere Barthes $(1961=1972: 72)-$ cuya exposición, aunque brillante, se aproxima mucho a la de Meleuc-, una especie de «economía métrica del pensamiento». El autor de máximas sería capaz de producir una cantidad ilimitada de combinaciones merced al juego permitido por un pequeño número de procedimientos - como un músico con las siete notas de la escala, apunta Truchet (1967: XLVIII) - Pero, además del rechazo de los deícticos, la insistencia en los sustantivos y el protagonismo del infinitivo y de las puras cópulas («est», «il y a»), hay que tener en cuenta también otras técnicas, entre las cuales destacan las figuras propias de la disposición sintáctica.

En efecto, los paralelismos, quiasmos, falsas simetrías, paradojas y proporciones rigurosas $(\mathrm{A}: \mathrm{B}=\mathrm{C}: \mathrm{D})$ revelan el funcionamiento esencialmente binario de la máxima, una forma que obliga al lector a dirigir su atención hacia los artificios de «distribución» de los componentes, y que, gracias a las relaciones casi matemáticas que establece entre ellos, busca la semejanza dentro de la disimilitud, lo metafórico en el seno de lo antitético, y viceversa. No es casual, en este ámbito, el uso constante del modelo de la identidad restrictiva o reductora ( $\ll \mathrm{X}$ no es más que $Y »)$, que permite ratificar a contrario la idea de la pertenencia, intentando esclarecer las confusiones implícitas en el mismo logos: dicha fórmula, según Starobinski (1964: 11), actúa como una cuchilla afilada que divorcia ser y parecer por disociación analítica, buscando tras los fenómenos y sus máscaras los componentes simples y las fuerzas universales. Pierssens (1971), desde una perspectiva vagamente marxista — partiendo de la base de que toda ideología se concibe a sí misma bajo la forma de la universalidad-, afirma precisamente que la máxima es una relación de al menos dos términos («corazón» y «sinceridad», «vicio» y virtud») que, tomados separadamente, son universales, sobre los cuales se ejercen reglas precisas de validación; la máxima sería, desde este punto de vista, el emblema formal propio de todo 
deseo de estabilidad axiológica, emblema tras el cual se vislumbraría la pretensión que tiene todo orden de dotarse de una escritura que lo resuma y lo garantice, y que, de paso, «conquiste» al receptor por medio de una escenificación espectacular - a través de una especie de dictadura del espíritu. Fórmula algebraica del saber (Rigolot, 1978: 279), mónada preceptivo-reflexiva o absoluto catártico (Ariani, 1979: 150-152), la máxima sería, en definitiva, un ejercicio en la manipulación de términos morales, una suerte de teorema ético que transformaría lo cultural en natural y que haría cesar la hemorragia del flujo de los significados arropándola con el código. Además, al verse obligada a actuar dentro de un terreno conceptual ya conocido, no puede producir una gran originalidad de pensamiento, sino sólo innovar a partir de lo ya sabido, esforzándose por pervertir la tradición con las artes de la ironía - la connivencia, el guiño o la captatio animi- y de la hipérbole - la exageración, que no el engaño, nos advierte Gans (1975: 489), valiéndose de Fontanie-. Llevado al extremo lo que acabamos de decir, no tiene por qué sorprender que algunos «esencialistas» de la lengua francesa - véase Bally (1950: 344 ) - , conscientes de la riqueza de la cultura gala en dichos célebres, máximas y frases lapidarias, hayan visto en ella una tendencia connatural hacia el género; ni tampoco que otros, todavía más osados en su fundamentalismo o su fatalismo - por ejemplo, Mautner (1966: 813)—, lleguen a preguntarse si la máxima no será una forma espontánea (es decir, necesaria) del pensamiento humano.

La concepción según la cual el género responde a una mecánica rígida y superficial es antigua ${ }^{4}$, y es una prueba indirecta pero clara de esta idea el éxito de que iban a gozar los «recetarios» para la composición de máximas. Lanson (1909: 135), por ejemplo, nos da más de una fórmula; las más famosas: escójanse dos objetos o dos cualidades de dos mundos diferentes - $\mathrm{el}$ mundo moral y el mundo físico («amour» $\mathrm{y}$ «feu», «bon sens» y «bonne grâce»), por ejemplo-, y asóciense, o establézcase entre ellos un paralelismo o una proporción matemática ${ }^{5}$. Más recientemente, Benabou (1990: 254), portavoz oficial de OULIPO en este tema, imaginó una máquina que posibilitaría la fabricación de aforismos

4 Es ya presente, al menos, en el «Grand Siècle», como lo demuestra Mme de Sévigné; la epistológrafa elogia a su hija por haber sabido invertir «Nous n'avons pas assez de force pour suivre toute notre raison», de La Rochefoucauld, en «Nous n'avons pas assez de raison pour employer toute notre force», subrayando que La Rochefoucauld «serait honteux [...] de voir qu'il n'y avait qu'à retourner sa maxime pour la faire beaucoup plus vraie» (carta del 14 de julio de 1680).

5 El resultado: «L'amour, aussi bien que le feu, ne peut subsister sans un mouvement perpétuel», y «La bonne grâce est au corps ce que le bon sens est à l'esprit»; ambos ejemplos son tomados de La Rochefoucauld. 
(léase máximas) en serie, «machine aux produits potentiellement innombrables», gracias a las manipulaciones y sustituciones permitidas por el carácter reversible de la máxima que ya explotaron en su momento Reboux y Muller (1930). La máquina en cuestión tendría como motor el casamiento de fórmulas - unión de lo que se encuentra separado y a la inversa: equivalencias, antítesis...-y palabras —que son la auténtica «carne» de la máxima-; en cuanto a su finalidad, se trata de demostrar una de las funciones principales del lenguaje: la creación de conexiones inexistentes. Ni que decir tiene que el propósito último (se notará que extremadamente banal) de oulipianos y oulipistas es la democratización de los productos de la cultura, y en particular de la «escritura», palabra que prefieren, claro está, a la de «literatura»: «au lecteur maintenant de se mettre au travail: la philosophie, comme la poésie, doit être faite par tous» Benabou (1990: 269). Por supuesto, que seamos buenos o malos escritores es harina de otro costal.

Se notará, sin embargo, que el hecho de negar el contenido de la máxima por desviación o por inversión no hace explotar para nada el marco en el que aquélla se mueve, pues el lector de una máxima, original o transformada (de La Rochefoucauld, de Éluard o de Péret) retendrá siempre, de entrada, la forma de un contenido. Como muy bien afirma Missac (1975: 144) a propósito de la cita sentenciosa, es difícil liberarse de los esquemas de la ideología cuando los de la retórica conservan todo su poder. Lautréamont juega, corrigiéndolos, con Pascal, La Rochefoucauld, La Bruyère o Vauvenargues - y enlaza, así, para oponerse a las «Grandes Têtes Molles» del Romanticismo, con la gran tradición de la poesía impersonal-, pero no consigue que el texto primitivo pierda su plausibilidad. Uno de los mejores Genette (1982) nos recuerda que no hay progreso sin plagio; y el mejor Lafond (1986: 133-134), que no basta con generalizar, asociar lo físico y lo moral u oponer palabras de sentido parecido para obtener las Maximes de La Rochefoucauld. En definitiva, reducir la máxima a una «proporción matemática» o a una «ecuación», como lo hacen, respectivamente, Lanson y Camus $(1944=1990)$ —añadámosles, al menos, Meleuc, Barthes y Benabou - significa no percibir que una de las mejores propiedades del género es su sorprendente ambigüedad.

\section{LA MÁXIMA COMO TEXTO}

Dicho de otro modo: la máxima es subjetiva, palabra de alguien que no se ausenta, sino que lo finge. Pensar lo contrario es no tener en cuenta la evolución del género, cuyos dos elementos constitutivos 
-impersonalidad y eternidad- desaparecen a partir de La Rochefoucauld, momento en el que empieza a desbaratarse la concepción inmanente de la naturaleza humana, la cual se socializa y se politiza, como lo demuestra ya Chamfort (Nemer, 1982: 489). No vamos a negar que Lafond (1983: 723) exagera al pretender que la presencia reiterada de la primera persona en la última de las Réflexions de La Rochefoucauld sitúa en la perspectiva del discurso personal, como por efecto de feed-back, todo el libro; pero lleva probablemente razón al apuntar que, si la máxima es absoluta, es por convención genérica, y que en la época clásica todo el mundo debe cubrirse bajo el escudo de lo general ${ }^{6}$. Y es que tras la máscara de la pluralidad y de la abstracción —de sus dramatis personae («ils», «nous», «on»)—- hay un sujeto, un Deus absconditus que no acaba de librarse, y que presenta su «discours» según el modelo estilístico de la «histoire» (Doubrovsky, 1980: 220). Ciertamente, la impersonalidad del conocimiento abstracto es confortable y protectora, y no parece desatinado ver en ella una forma de compensación (Starobinski, 1962: 38; Barthes, 1975: 181), como si pudiera conseguirse una salvación provisional a través del estilo: el estatismo y el equilibrio, el trazado sólido y agudo de la máxima parecen reducir el vértigo y la angustia latentes en todo universo moral a un accidente (un sustituto) limitado; he aquí, sin duda, una de las principales motivaciones psicológicas de la propensión de muchos al género, tal vez extrapolable a todo tipo de escritura. Es peligroso querer escudriñar demasiado profundamente en nosotros mismos, y necesitamos antídotos estéticos que regulen y controlen la desesperanza.

Contrariamente, pues, a lo que pretenden muchas voces, en la máxima no habla el autor como hombre, sino el hombre como autor, ya que por mucho que el discurso sentencioso tienda a ser por naturaleza discurso teórico, éste se convierte las más de las veces en autoteoría. La lingüística de la enunciación nos ha enseñado a desconfiar de las fórmulas objetivas, y a reconocer tras una descripción impersonal una pintura enormemente subjetiva, de la misma forma que un relato asumido por el «yo» puede adoptar un punto de vista universalista. Kerbrat-Orecchioni (1980: 153-154) nos advierte al respecto de las

6 Se recordará a propósito el precepto pascaliano según el cual el «yo» (la expresión desnuda del pensamiento) es odioso. Una larga tradición, en la literatura francesa (especialmente la moralista) defiende precisamente el uso del pronombre «on» con el fin de evitar la primera persona, ya sea del singular (considerada inoportuna), ya sea del plural (calificada de petulante cuando concierne a un sujeto único). 
imposturas del discurso con pretensiones objetivas - también del discurso científico-, las cuales han sido denunciadas reiteradamente desde diferentes escuelas y perspectivas. Con gran espíritu de síntesis, Kerbrat-Orecchioni abunda en la idea de que reducimos impropiamente la pareja subjetivo/objetivo, respectivamente, a los procedimientos de exhibición/ocultación gramatical del sujeto enunciador. Porque cuando decimos que un enunciado es objetivo podemos querer significar dos cosas diferentes, y a menudo excluyentes: podemos denotar, por una parte, una propiedad interna al enunciado - la ausencia de marcas que inscriben el locutor o narrador-, y, por otra parte, su adecuación referencial - generalmente evaluada por el receptorDicho de otro modo, se puede ser, a la vez, objetivo (en el primer sentido) y comprometerse (no ser neutral), o inversamente (subjetivo y neutral), caso sin duda más difícil (por no decir imposible) de encontrar, al menos en el ámbito de la literatura.

No en vano, el interés actual por el «présupposé» i el «sous-entendu» (Ducrot, 1969), lo implícito y lo no dicho, se encuentran en el centro de un movimiento generalizado dentro de la linguística que tiene por principio el reconocimiento de la subjetividad. Para KerbratOrecchioni (1980: 169), la existencia misma de una Historia en el sentido de Benveniste es inadmisible, o sólo tolerable como el «horizonte mítico» (en el sentido de ideal imposible) de ciertos discursos. Naturalmente, la manifestación del locutor en el enunciado tiene grados y modalidades diversos, pero no es difícil reconocerla en la máxima. Por ejemplo, en el uso continuado del presente - tiempo provisto de un claro valor deíctico: la presencia de «ahora» sugiere un «yo» narrador (Genette, 1983: 55)—, del pronombre «nosotros» —el principal problema planteado por el discurso de la máxima según Lewis (1972: 45) ${ }^{7}-$, y de las expresiones atenuantes (a menudo, a veces, habitualmente, parece que), que suavizan la tendencia exagerada a la universalización.

No olvidemos, en fin, que ya a partir de La Rochefoucauld la máxima se dedica a desviar el cuerpo trivializado de las opiniones recibi-

7 Por ejemplo, dice Lewis a propósito del proceso enunciativo generado por el pronombre, si escogemos la máxima 38 de La Rochefoucauld («Nous promettons selon nos espérances, et nous tenons selon nos craintes»), «we can distinguish between two temporal dimensions, the immediate present of the enunciatory process and the durative present of the stated universal, and correlatively between two subjects, we who read or write this statement and we who, as Men, act in accord with the principle that is enunciated. The appareance of the enunciatory dimension poses a problem which one encounters in the act of reading". 
das, las cuales no serán convocadas más que para ser transgredidas por la acidez corrosiva de una mirada singular. Con sus constantes rupturas de previsibilidad, la máxima codificará progresivamente entre las cosas una relación no razonable o antinatural - extravagante - que, como ha sabido muy bien notar Nemer (1982: 487), suscitará la misma desconfianza que los tropos, cuyo uso debe ser vigilado a causa de su propensión a lo artificial y lo ambiguo. Léase, si no, como prueba este rico fragmento de La Rhétorique ou l'Art de parler, del Padre Lamy (1701: 328):

J'ai toujours remarqué que c'est le caractère des petits génies que l'affectation dans le discours; un esprit élevé, solide, n'établit pas sa réputation sur des phrases ou des expressions qui n'ont que le tour rare. Pourquoi ne pas dire les choses d'une manière naturelle? Pourquoi dire obscurément que 'nous nous devenons plus chers à mesure que nous sommes plus près de nous perdre' pour dire que quand on est vieux, et sur le point de mourir, on ménage davantage la vie? [...] On doit partout éviter ce qui s'appelle phrase et faire consister l'esprit à dire des choses raisonnables, et à les dire d'une manière naturelle [...] Tout ce qui est recherché ou semble l'être, qui est tiré de loin, n'a point une certaine naïveté qui se fait aimer et estimer.

Lamy entrevé en la oscuridad connatural a la máxima un artificio voluntariamente mistificador, idea que le lleva a una interpretación harto reductora del género: en efecto, tenemos el derecho a juzgar como demasiado simple o monosémica su glosa del ejemplo de La Rochefoucauld que él mismo cita.

A la luz de todo lo que venimos diciendo, se comprenderá por qué una máxima nos puede gustar o desagradar independientemente del valor de verdad que estemos dispuestos a reconocerle. Pues, si actualmente consideramos la máxima como un texto en el pleno sentido del término, es gracias a un fenómeno de recuperación estética, magistralmente estudiado por Genette (1991: 26). El insigne narratólogo reclama la entrada en el panorama de la teoría literaria de una poética condicionalista, que daría cuenta de textos no incluidos en las listas canónicas de las poéticas esencialistas, para las cuales sólo pertenecen a la literatura «des textes a priori marqués du sceau générique, ou plutôt archigénérique, de la fictionnalité et/ou de la poéticité». Memorias, ensayos, máximas... - formas que más de veinte años atrás (en «Frontières du récit») Genette (1969) incluiría ya en el régimen del «discours»- pueden entrar a formar parte del ámbito de la literatura condicional, que, como tal, relega la función primera (documental, 
moral, polémica) de ciertos textos en beneficio de sus méritos estrictamente literarios.

\section{MÁXIMA, WITZ Y ADIVINANZA}

\subsection{Máxima y Witz}

Consideremos esta máxima de Proust: «Chacun a sa manière propre d'être trahi, comme il a sa manière de s'enrhumer». La declaración "pertenece" a Marcel, el protagonista narrador de la Recherche, y está situada a comienzos de Albertine disparue (Proust, 1987-1989: IV, 10), cuando Marcel constata que la huida de su amante excita en él nuevos ataques de celos. La frase, de una agudeza casi irreverente por el contacto que establece entre la realidad moral y la fisiológica (una de las destrezas en las que destaca Proust, que fue muy buen alumno de La Rochefoucauld), podría servir para defender las innegables dotes humorísticas del autor, contra aquellos que lo creen poco dado a la broma. Aquí, sin embargo, lo que nos interesa señalar son los vínculos entre dos formas aparentemente alejadas, unos vínculos que tienen mucho que ver con las finalidades lúdicas que también puede revestir la máxima.

Digamos, para empezar, que el parentesco entre máxima y witz ha sido puesto de relieve desde tiempos lejanos, y que no es debido, como se cree a menudo, a Freud - lo que no resta mérito a su estudio El chiste y su relación con el inconsciente, de 1905, donde cita agudezas de su apreciado y, en algunos aspectos, precursor Lichtenberg. Ya Quintiliano, en su Institutio oratoria, calificaba la sententia - la antecesora de la futura máxima- de rasgo luminoso (lumen), por lo que Compagnon (1979: 152) no se equivoca al considerar que, al menos en muchos contextos, la mejor traducción moderna del término latino sería la de «mot d'esprit». Entre las contribuciones sobre el witz posteriores a Freud destacan la de Jolles en Formes simples $(1930=1972)$ y de Todorov en Les genres $d u$ discours (1978), autores a los que volveremos en el subapartado siguiente ${ }^{8}$.

8 Se diría que la cuarta y última parte del libro de Todorov (1978: 223-310), dedicada a los géneros no literarios, está inspirada en el estudio de Jolles, a pesar de la perspectiva netamente diferente que adoptan uno y otro (socio- o etnológica el alemán, y más estrictamente retórica el búlgaro). El excelente artículo de Tiefenbrun (1980) demuestra que máxima y wit (el equivalente inglés del witz), pese a las diferencias, operan dentro de un mismo campo formal y conceptual. 
Jolles (1930: 198) define el witz (la traducción francesa opta aquí no por «mot d'esprit», sino por «trait d'esprit») como «la forme qui dénoue les choses, qui défait les noeuds», fórmula con la que subraya la disposición mental inherente al género, así como su carácter insensato y contradictorio, impensable e inconveniente. Al destruir las reglas prescritas por la moral práctica y las buenas costumbres, el witz. puede incluso descomponer cualquiera de las demás «formas simples» -dentro de las cuales no incluye Jolles las formas «sabias» (la máxima o el retrato, por ejemplo)—, y ello merced al uso que hace de las exageraciones, las transposiciones y la ironía; «l'univers du comique - dice más allá el crítico- est un univers où les choses se nouent en se défaisant ou en se dénouant» (Jolles, 1930: 207). El placer del witz, dirá Calvino (1967) en «Cibernética y fantasmas», nace gracias a las posibilidades de permutación y de transformación implícitas en el lenguaje - Calvino estaba entonces bajo el influjo de Propp y de Greimas (y el OULIPO no quedaba lejos). Podríamos, pues, decir que, análogamente al witz, la máxima pretende ser provocadora e irónica (en la tradición del dictum latino), y que uno de sus resortes principales (como ya hemos visto más arriba, valiéndonos de Lanson y Benabou) consiste precisamente en unir lo que se encuentra habitualmente separado y en separar lo que normalmente está unido.

Por su parte, Todorov (1978) distingue en el witz tres niveles que no son difíciles de percibir en la máxima. El primero se refiere a la «tendencia» del witz, en general agresiva, nunca elogiosa. El segundo concierne al trabajo de figuración, que atrae al oyente (en la máxima, al lector) y lo conduce a buscar una nueva interpretación, especialmente a través de la figura de la contradicción. El tercero lo ocupa el trabajo de simbolización, que consiste en inducir un segundo sentido (el «sens imposé») a partir del primero (el «sens exposé»); en este capítulo, Todorov se dedica ante todo al análisis de la jerarquía de los sentidos y su papel en la producción del «esprit», subrayando la importancia del orden de aparición de los elementos del witz, orden que contribuye en gran manera al efecto de sorpresa.

En cuanto a las divergencias entre ambas formas, cabe matizar que, así como el witz exhibe sus finalidades lúdicas y pretende voluntariamente provocar la risa del destinatario desafiando las leyes sociales y morales -l horizonte de expectativas del oyente-, la voluntad de la máxima es más intrínsecamente de orden conceptual, al querer poner a prueba las leyes lógico-representativas (Biason, 1990: 29) —que éstas no resistan a su acción corrosiva y que el resultado sea más o menos lúdico es, por así 
decirlo, facultativo- No hay que descuidar, además, otra discrepancia de peso por lo que se refiere a los procesos de producción y de recepción, el terminus a quo y el terminus ad quem. Mientras que, en cuanto al primer aspecto, la génesis de la máxima parece encontrarse por encima de las circunstancias personales y psicológicas de su autor (ya hemos advertido, sin embargo, que esta ley debe ser en parte contestada), el witz surge de la carga de tensión y la imposibilidad de liberarla si no es a través del lenguaje, el cual cumple en este caso, y de forma indeliberada, la función de retorno a la calma o de relaxatio animi. El segundo aspecto al que hemos aludido deriva estrechamente del primero: si la máxima se presta a una reutilización dialógica y continuada, el witz está destinado a un consumo inmediato y ocasional, monológico; una vez proferido, vuelve como un boomerang a su locutor, en una especie de viaje autocomunicativo - el hecho de que podamos escucharlo o leerlo vendría a ser una perversión de su designio original.

\subsection{Máxima $y$ adivinanza}

Fijémonos en esta otra máxima, también de Proust, y perteneciente asimismo al discurso interior del narrador protagonista de la Recherche: «Il y a une chose plus difficile encore que de s'astreindre à un régime, c'est de ne pas l'imposer aux autres» (Pronst, 1987-89: III, 482). En este caso, Marcel tiene como punto de mira no ya a sí mismo y sus enfermedades del corazón, sino al ridículo $M$. de Cambremer, que pretende hacerle beneficiar de los hábitos gastronómicos que tanto bien hacen a su hermana asmática. El enunciado responde al esquema formal implícito - ampliamente utilizado por la máxima, y constitutivo de la adivinanza - de pregunta-repuesta (en su estructura profunda: «¿Qué es más difícil que seguir un régimen? No imponerlo a los demás»). Consideremos ahora el siguiente enunciado:

\footnotetext{
Une heure n'est pas une heure, c'est un vase rempli de parfums, de sons, de projets et de climats. Ce que nous appelons la réalité est un certain rapport entre ces sensations et ces souvenirs qui nous entourent simultanément (Proust, 1987-89: IV, 467-468).
}

Destaca su forma definitoria - también intrínseca a la adivinanza, y claramente relacionable con la característica anterior-, aquí subrayada 
por la presencia reiterada del verbo ser (distribuidor de la existencia como ningún otro) y la negación implícita («n'est pas», «ce que nous appelons») de las propiedades que todo diccionario atribuiría a los conceptos en cuestión: así, «una hora» y «la realidad» presentan, en máxima, atributos inesperados que decepcionan y traicionan la definición consensuada y socialmente instituida, estándar, de estos términos. La máxima, decía Barthes (1964: 232-234) hablando de La Rochefoucauld con poco aprecio -es sabido que prefiere a La Bruyère, a quien reconvierte, en beneficio propio, en autor de «fragmentos»...-, es una metáfora pura (una definición), y por eso tendría una «sequedad algebraica». No es inútil recordar, con Truchet (1967: XIV), el paralelismo evidente entre la máxima y la eclosión, en la Francia del siglo XVII, de los grandes diccionarios.

Respecto de la primera de las dos características evocadas, el esquema pregunta-respuesta, es interesante lo que nos dice Jolles (1930: 105-106) sobre las relaciones entre el mito (también «forma simple», a su parecer) y la adivinanza - aunque, en conjunto, su estudio sobre esta Forma es decididamente menos inspirado que el que dedica al wit. Jolles apunta que la diferencia exterior entre mito y adivinanza consiste en que el primero es una respuesta a una pregunta previa -en relación siempre con la naturaleza profunda de los fenómenos del universo-, mientras que la segunda es una pregunta que exige una respuesta ya cifrada - y por eso el uno lleva «los colores de la libertad» (es activo) y la otra «los de la coacción» (es pasiva y opresiva) ${ }^{9}$.

En cambio, la segunda característica, la adivinanza como definición, es tratada remarcablemente por Todorov en «La devinette» (1978) - y aquí recobramos el nervio y la vena que nos ha faltado en su ensayo sobre el «mot d'esprit» (sorprende que Todorov sea un autor tan irregular). Después de hacer una revisión muy crítica del discurso de la adivinanza a partir de la bibliografía que ya ha generado, Todorov señala que su rasgo constitutivo es que presenta la estructura de una definición dialogada invertida. Podríamos hacer de las dos réplicas - la frase o parte presente, por un lado, y la palabra o parte ausente, por otro (la pregunta y la respuesta de Jolles) - una única frase afirmativa, con lo cual obtendríamos una relación de

9 Son, asimismo, interesantísimas les consideraciones con que Compagnon (1979: 133) vincula, a partir de la noción de verosimilitud, la $\gamma w \omega \mu \eta$ aristotélica con el mito platónico; aquélla habría venido a suplantar a éste último - sustituyendo su origen mágico o religioso por el consentimiento universal de la humanidad-, pero sin cambiar su función (dar una imagen de la realidad). 
sinonimia entre el predicado (la primera réplica, el «symbolisant», dice Todorov más adelante) y el sujeto (la segunda, el «symbolisé»). Naturalmente, esta relación, com apuntábamos más arriba, no es oficial o estatuida por los diccionarios (no es «científica»), sino lateral (metafórica, sinecdóquica, paradójica, siléptica... trópica), y así llegaremos a la conclusión de que la réplica de la adivinanza es intrínsecamente polisémica: la sinonimia de los dos predicados esconde la polisemia del significante. La adivinanza, pues, compartiría con el witz la audacia en la definición, y, si no aplicáramos a audacia los rasgos de «extravagante», «espectacular» u «oscuro», también la compartiría con la máxima - la cual, pese a su carácter literario, suele estar provista de un mayor aparato de garantías lógicas. No hay que olvidar, además, la consecuencia inevitable derivada de la diferencia entre sustitución (la adivinanza exige suplantar una réplica por otra) y yuxtaposición (es el caso de la máxima, el witz y la definición, que no ocultan la denominación del concepto del que tratan): la adivinanza «impone» al destinatario una acción verbal inmediata — de ahí, como hemos visto, la tiranía que ve en ella Jolles-, mientras que la máxima, más solícita, le «invita» a una actividad lenta y reflexiva.

Es obvio que buena parte de las diferencias entre máxima y adivinanza, y también entre máxima y witz y máxima y proverbio, dependen del carácter escrito de una, por oposición al carácter esencialmente oral de los demás (sobre todo de la adivinanza y el proverbio, pero también del witz). No parece fuera de lugar en este contexto recordar las propiedades que Derrida (1972: 372-378) atribuye al signo escrito. Se trata de una marca que: 1) se puede repetir en ausencia no sólo del sujeto que la emitió en un contexto determinado, sino también de un receptor concreto; 2) se puede leer en un contexto diferente de su contexto real, independientemente de la intención del escritor; y 3) está subordinada a un espacement en doble sentido: por una parte, se encuentra separada del resto de signos en una cadena particular y, por otra, de referencia presente (es decir, se puede referir únicamente a algo no presente en ella) ${ }^{10}$.

10 Quizás a la luz de estas remarcas podremos comprender por qué la clara frontera que tanto la máxima como la adivinanza establecen entre ser y parecer (pues ambas se erigen en contra de la definición normativa) es de signo contrario; en efecto, mientras que la adivinanza se encuentra en el lado del parecer - se basa en un conocimiento perceptivo de las apariencias: le preocupa lo que parece lo que es-, la máxima se encuentra en el lado del ser — pretende decir lo que es lo que parece, es decir, lo verdadero. 
Concluiremos volviendo a Todorov (1978: 236), y en concreto a su esquema recapitulativo a doble entrada. En él reúne las tres figuras que a lo largo de su recorrido ha detectado en los diferentes tipos de adivinanzas, cada una de las cuales invierte una verdad o truismo subyacente. Así, las inverosimilitudes invierten los lugares comunes, como las paradojas invierten las tautologías, y las contradicciones, los entimemas. Podríamos decir, llevando este esquema a nuestro terreno, que la máxima, como la adivinanza, pretende convertir la paradoja (la definición desviada) en una nueva doxa - y esta vez no vamos a contradecir a Barthes (1975: 126-127) ${ }^{11}$.

\section{Referencias bibliográficas}

ARIANI, M. (1979). «La trasgressione e l'ordine: L'Orbecche' di G. B. Giraldi Cinthio». Rassegna della letteratura italiana 83: 1-3, 117-180.

BALly, Ch. (1950). Linguistique générale et linguistique française. Berna: A. Francke.

BARTHES, R. (1961=1972). «La Rochefoucauld: réflexions ou sentences et maximes». En Le degré zéro de l'écriture, suivi de Nouveaux essais critiques, 69-88. París: Seuil. 69-88.

- (1964). «La Bruyère». En Essais critiques, 221-237. París: Seuil.

- (1975). Roland Barthes par Roland Barthes. París: Seuil.

Benabou, M. (1990). «Un aphorisme peut en cacher un autre». En La Bibliothèque oulipienne 1, 252-269. París: Seghers.

BenNington, G. (1985). Sententiousness and the Novel. Laying down the Law in Eighteenth-Century French Fiction. Cambridge-New York-Melbourne: Cambridge University Press.

BENVENISTE, É. (1950=1966). «La phrase nominale». En Problèmes de linguistique générale, 151-167. París: Gallimard.

BENVENISTE, É. $(1959=1966)$. «Les relations de temps dans le verbe français». En Problèmes de linguistique générale, 237-250. París: Gallimard.

BESA, C. (1994). «Máxima y Relato: conjunciones y desacuerdos», Paremia $3,45-51$.

11 Opresiva y represiva (evidente), la doxa es Medusa, que petrifica a quien la mira. Contra los productos «endoxales» de la cultura de masas, la solución barthesiana es bañarse y lavarse acto seguido con un poco de discurso detergente. Barthes sostiene, como escritor que es, que su espacio es el de la paradoja, y recuerda de la mano de Diderot que la palabra significaba en el siglo XVIII «une proposition contraire à l'opinion commune». 
- (en prensa): «Le désir de la loi/Les lois du désir: maxime et motivation dans la Recherche». Actes del coloquio internacional «Désir d'aphorismes», celebrado del 6 al 8 de abril de 1995 en la Faculté des Lettres de la Université Blaise-Pascal, Clermont-Ferrand.

BiAson, M. T. (1990). La massima o il «saper dire». Palermo: Sellerio.

CALVINo, I. (1967=1983). «Cibernética y fantasmas. Apuntes sobre la narrativa como proceso combinatorio. En Punto y aparte: ensayos sobre literatura y sociedad, 214-234. Barcelona: Bruguera.

CAMus, A. (1944=1990). «Introduction aux Maximes de Chamfort». En Essais, 1.099-1.109. París: Gallimard, «Bibliothèque de la Pléiade».

Compagnon, A. (1979). La seconde main ou le travail de la citation. París: Seuil.

DeRridA, J. (1972). «Signature Évenement Contexte». En Marges de la philosophie, 367-393. París: Minuit.

DOUBROVSKY, S. (1980). «Vingt propositions sur l'amour-propre: de Lacan à La Rochefoucauld». En Parcours critique, 203-234. París: Galilée.

DuCROT, O. (1969). «Présupposés et sous-entendus». Langue française 4, 30-43.

FREUD, S. (1905=1971). Le Mot d'esprit et ses rapports avec l'inconscient. París: Gallimard.

GaNs, É. (1975). «Hyperbole et ironie». Poétique 24, 488-494.

GeNETTE, G.(1969). «Frontières du récit». En Figures II, 49-69. París: Seuil. - (1982). Palimpsestes. París. Seuil.

- (1983). Nouveau discours du récit, París, Seuil.

- (1991). Fiction et diction. París. Seuil.

Jolles, A. (1930=1972). Formes simples. París: Seuil.

KeRBRAT-OrecCHIONI, C. (1980). L'énonciation de la subjectivité dans le langage. París: Armand Colin.

LAFOND, J. (1983). «La Rochefoucauld et les enjeux de l'écriture». Papers on French Seventeenth Century Literature 10: 19, 711-731.

- (1986). La Rochefoucauld. Augustinisme et littérature (3 ${ }^{\text {ème }}$ édit. revue, corrigée et augmentée). París: Klincksieck.

LAMY, Le père B. (1701). La Rhétorique ou l'art de parler (4 ${ }^{\mathrm{ème}}$ édition revue et augmentée).

LANSON, G. (1909). «Les 'formes fixes' de la prose: portraits et maximes». En L'Art de la Prose, 126-139. París: Librairie des Annales.

LA RochefoucAuld (1964). Oeuvres complètes. París: Gallimard, «Bibliothèque de la Pléiade».

LewIS, Ph. E. (1972). «The discourse of the Maxim». Diacritics, 41-48.

MAUTNER, F. H. (1966). «Maxim(e)s, sentences, fragmente, aphorismen». En Actes du IV Congrès de L'AILC. 812-819. París-La Haya: Association Internationale de Littérature Comparée.

MeleuC, S. (1969). «Structure de la maxime». Langages 13, 69-99.

Missac, P. (1975). «Éloge de la citation ou De la citation conçue comme instrument de la critique: une étude issue des idées de Walter Benjamin et appuyée sur des textes d'Edmond Jabès». Change 22, 133-150. 
NEMER, M. (1982). «Les intermitences de la vérité. Maxime, sentence ou aphorisme: notes sur l'évolution d'un genre». Studi francesi 26, 484-493.

Perelman, Ch. y Olbrechts-Tyteca, L. (1988). Traité de l'argumentation. La nouvelle rhétorique. Bruselas: Éditions de l'Université de Bruxelles.

PIERSSENS, M. (1971). «Fonction et champ de la maxime». Sub-Stance 0, 1-9. PRoust, M. (1987-1989). À la recherche du temps perdu. París: Gallimard, «Bibliothèque de la Pléiade», 4 vols.

Reboux, P. y Muller, Ch. (1930). À la manière de... París: Grasset.

Rigolot, F. (1978). «Sémiotique de la sentence et du proverbe chez Rabelais». Études rabelaisiennes 14, 277-286.

SÉVIGNÉ, Madame de (1972-1978). Correspondance. París: Gallimard, «Bibliothèque de la Pléiade», 3 vols.

Starobinski, J. (1962), «Complexité de La Rochefoucauld». Preuves 135, 33-40.

- (1964). «Introduction» a La Rochefoucauld: Maximes et Mémoires, 7-35. París: Union Générale d'Éditions.

Tiefenbrun, S. (1980). «Wit, beyond Freud, and the Maxims of La Rochefoucauld». Papers on French Seventeenth Century Literature 13: $1 / 2,239-283$.

ToDorov, T. (1978). Les genres du discours. París: Seuil.

TRUCHET, J. (1967). «Introduction» a La Rochefoucauld: Maximes suivies des Reflexions diverses, du Portrait de La Rochefoucauld par lui-même et des Remarques de Christine de Suède sur les 'Maximes', 7-72. París: Garnier. 